\title{
PODER Y VIOLENCIA EN LAS COMUNIDADES INDÍGENAS
}

\author{
POWER AND VIOLENCE AT INDIGENOUS COMMUNITIES
}

Thaís Janaina Wenczenovicz

Docente Adjunta - Depto Ciências Humanas e Sociais - da Universidade Estadual do Rio Grande do Sul/UERGS. E-mail: t.wencze@terra.com.br

Narciso Leandro Xavier Baez

Coordenador Acadêmico-Científico do Centro de Excelência em Direito e do Programa de Mestrado em Direito da Universidade do Oeste de Catarina; Pós-Doutor em Mecanismos de Efetividade dos Direitos Fundamentais pela Universidade Federal de Santa Catarina; Doutor em Direitos Fundamentais e Novos Direitos pela Universidade Estácio de Sá, com estágio bolsa PDEE/Capes, no Center for Civil and Human Rights, da University of Notre

Dame, Indiana, Estados Unidos; Mestre em Direito Público; Especialista em Processo Civil; Juiz Federal da Justiça Federal de Santa Catarina desde 1996.

E-mail: narciso.baez@gmail.com

Recebido em: 07/02/2017

Aprovado em: 24/10/2017

RESUMEN: Para entender la violencia contra los pueblos indígenas en el Brasil contemporáneo, se hace necesario una análisis sistémica y de largo plazo, considerando su interrelación con el poder. El estudio objetiva analizar el poder y sus interrelaciones con la violencia ejercida en las comunidades indígenas. Poder utilizado en el proceso de ocupación y asentamiento, en los conflictos sobre la tierra, o en proceso de asentamiento, aculturación y asimilación. Para ese proceso de análisis se hace una mirada acerca de la Colonialidad del Poder, un concepto propuesto por Aníbal Quijano. El analiza, que, aún con la independencia de las colonias de los imperios ibéricos, el poder colonial se mantuvo. La violencia se configura a través de varias prácticas - fisica y simbólica. En la contemporaneidad, la violencia es fundamentalmente institucional, sea ya del estado brasilero reduciendo los derechos como la no demarcación de los territorios y la ejecución de obras de desarrollo que afectan a estos pueblos o por omisión. En cuanto al procedimiento metodológico se utiliza el bibliográfico-investigativo, acompañado de datos y bases estadísticas donde se emplea los indicadores de CEPAL, del IBGE y relatoría Violencia Contra los Pueblos Indígenas en Brasil - publicado por el Consejo Indigenista Misionario (CIMI).

Palabras-Claves: Comunidades Indígenas; Poder; Violencia.

ABSTRACT: In order to understand the violence against the indigenous towns in contemporary Brazil, a systemic analysis is necessary and of long term, considering their interrelation with the power. The objective study to analyze the power and its interrelations with the violence exerted in the indigenous communities. Power used in the process of occupation and settlement, in conflicts over land, or in the process of settlement, acculturation and assimilation. For this process of analysis, one looks at the Coloniality of Power, a concept proposed by Aníbal Quijano. $\mathrm{He}$ analyzes that, even with the independence of the colonies of the Iberian empires, colonial 
power remained. Violence is shaped by various practices - physical and symbolic. At the present time, violence is fundamentally institutional, whether of the Brazilian state, reducing the rights of non-demarcation of territories and the execution of development works that affect these peoples or by omission. As for the methodological procedure, the bibliographical-investigative is used, accompanied by data and statistical bases where CEPAL, IBGE and Violence Against Indigenous Peoples in Brazil - published by the Indigenous Missionary Council (CIMI) are used.

keywords: Indigenous Communities; Power; Violence.

SUMARIO: Introduccion; 1 Comunidades Indígenas en America Latina; 2 Poder y Violencia: conceptos y definiciones; 3 Violencia contra las Comunidades Indigenas Brasileras: reflexiones iniciales; Conclusion; Referencias Bibliograficas; Fuentes Electronicas.

\section{INTRODUCCION}

Imposible analizar la historia de América Latina sin tomar en consideración la presencia de las comunidades indígenas. Asentados en decenas de etnias y con matrices lingüísticas y costumbres diferenciadas denotan su singularidad en composición socio - histórica en muchos países de América Latina.

Concomitante a su historicidad acompañan a su trayectoria el poder y la violencia. Uno de los mayores desafíos que enfrenta la región en la búsqueda de la igualdad es la inclusión de los derechos de los pueblos indígenas entre las prioridades como política pública. Innumerables son los desafíos, pues viven en América Latina más de 800 pueblos indígenas, con una población cerca de 45 millones y, se caracterizan por su amplia diversidad cultural, demográfica, política, social y territorial (incluidas los pueblos en aislamiento voluntario) hasta la fuerte presencia en las zonas y asentamientos urbanos.

En gran parte de América Latina se constata la omisión de las poderes públicos en la implementación de los Derechos Humanos y Fundamentales a las comunidades indígenas, que asociada a la demora en la demarcación, protección y fiscalización de la tierras, corroboraban con la minimización cultural, resultando en violencia estructural, el hambre, la pobreza extrema y las enfermedades (incluyendo la muerte prematura de los niños indígenas) por falta de atención médica adecuada. La falta de saneamiento básico, asociada con la falta de agua potable está también entre las demandas de varios países en un intento de disminuir la violencia a los pueblos indígenas.

Agrega al contexto, el curso de la historia de los pueblos indígenas en América Latina, marcada por diferentes procesos y formas de injusticia y violencia institucionalizadas. Inicia por la negación de su cultura, transita a lo largo del tiempo por la negación de la trayectoria histórica y llega hasta los días de hoy señalados por el límite al ejercicio de los Derechos y, en consecuencia, de la ciudadanía.

El artículo se divide en tres partes. La primera aborda los elementos de la trayectoria histórica-política y social de las comunidades indígenas en América Latina. El segundo, traza elementos acerca del concepto de poder y violencia. En la tercera y última parte son presentados bases de datos estadísticos que involucran a comunidades indígenas en cuanto a la violencia.

En cuanto al procedimiento metodológico se utiliza el método bibliográfico investigativo, acompañada de documentos jurídicos como el Convenio no 169 sobre Pueblos Indígenas y Tribales en Países Independientes de la Organización Internacional del Trabajo (OIT, 1989), ratificada por Brasil a través del Decreto no 143 del 25 de julio de 2002; la Declaración de la ONU Derechos de los Pueblos Indígenas (ONU, 2007); la Convención sobre la Protección y Promoción de la Diversidad de las Expresiones Culturales, ratificada por el Congreso Nacional en diciembre de 2006 y promulgada en el país por Decreto Ley n ${ }^{\circ} 6.177$, del 01 de agosto de 2007; la Convención para la Salvaguardia del Patrimonio Cultural Inmaterial, ratificada por 
Decreto $\mathrm{n}^{\circ}$ 5.753, del 12 de abril de 2006; cartas y decretos de la Comisión de Derechos Humanos y Minorías (CDHM) y Constitución de Brasil de 1988. Para la comparación de datos y bases estadísticas se emplea los indicadores de la Comisión Económica para América Latina y el Caribe (CEPAL), del Instituto Brasilero de Geografía y Estadística (IBGE) y relatoría Violencia Contra los Pueblos Indígenas en Brasil - datos de 2015 - publicado por el Consejo Indigenista Misionario (CIMI).

\section{COMUNIDADES INDÍGENAS EN AMÉRICA LATINA}

Durante mucho tiempo las comunidades indígenas en América Latina eran vistas como un obstáculo para el desarrollo. Asolado por enfermedades, pérdida de sus territorios y procedidos del proceso de aculturación, asimilación y confinados en tierras o reservas indígenas. Estas imágenes que se han consolidado en violencia física y simbólica se hicieron populares en el imaginario contemporáneo. ${ }^{1}$

Por otro lado diversos segmentos atribuían a las comunidades indígenas la concepción de que estos eran un obstáculo al desenvolvimiento nacional en razón de no acompañar a los objetivos culturales, económicos y políticos tomados como 'civilizadores'. Obsérvese también que la legislación al indígena siguió por mucho tiempo en contradicción conceptual - de un lado busca promover la tutela de los intereses de las sociedades indígenas y por otro aumenta el grado de estigma y segregación. ${ }^{2}$

En ambas imágenes que se dispersan en la imaginación contemporánea, hay un componente común: la casi extinción de la población nativa de América Latina- ya sea físico o étnico cultural. En el primer caso, la población indígena, predominante en la región en los tiempos de la colonización, hoy representa cerca del 10\% de la población de América Latina. Esto se encuentra principalmente concentrada en cinco países: Bolivia, Ecuador, Guatemala, México y Perú. En el segundo caso, los nativos de América Latina pasaron por un proceso de aculturación tan significativo que apenas se puede hablar hoy de los grupos étnicos e indígenas auténticos. Se perdió mucho su identidad teniendo en vista la eliminación de grupos humanos enteros, pasando por el proceso de aldea miento, aculturación y asimilación.

Debido a la explotación colonial, los indios perdieron sus referencias materiales/estructural-tierras, fuente de su supervivencia e inmateriales - aspectos artísticos, lingüísticos y religiosos. La suma de estos elementos indica la llegada de la pobreza y llevó al deterioro de su condición de vida, colocándolos en una condición de exclusión y marginación social. En algunos países, como Brasil, el Estado demarco las tierras indígenas en todo el territorio nacional, en un intento de garantizar la subsistencia. Sin embargo, en muchos casos, el tamaño de la reserva (tierras indígenas) no es suficiente para albergar a todas las comunidades nativas con dignidad. Según Quijano,

Uno de los ejemplos más claros de esta tragedia de equivocaciones en América Latina es la historia de la llamada cuestión nacional. Dicho de otro modo, del problema del moderno Estado-nación en América Latina. Naciones y Estados

\footnotetext{
${ }^{1}$ Para muchos autores, pensar el colonialismo y imperialismo en el siglo XXI no se trata de un recuerdo anacrónica y paranoico de la izquierda tercermundista. En diferentes direcciones, la continua elaboración intelectual sobre ambos procesos que marcaron el pasado de los países colonizados ofrecen interpretaciones interesantes sobre la persistencia de diferentes niveles de desigualdades globales en el presente. Analizar tanto los resquicios y las continuidades de las relaciones coloniales y imperiales, como sus diferentes formas contemporáneas de reproducción, pueden auxiliar a comprender los complejos niveles y escalas de injusticias estructurales, en los campos económico y cultural (FRASER, 2001).

${ }^{2}$ Vease importantes contribuciones en A colonialidade do saber: eurocentrismo e ciências sociais. Perspectivas latino-americanas. Edgardo Lander (org). In: Colección Sur Sur, CLACSO, Ciudad Autonoma de Buenos Aires, Argentina, 2005.
} 
son un viejo fenómeno. Sin embargo, aquello que llamamos el moderno Estadonación es una experiencia muy específica. Se trata de una sociedad nacionalizada y por eso políticamente organizada como un Estado-nación. Implica a las instituciones modernas de ciudadanía y democracia política. Es decir, implica una cierta democracia, dado que cada proceso conocido de nacionalización societal en los tiempos modernos ha ocurrido solamente a través de una relativa (o sea, dentro de los límites del capitalismo) pero importante y real democratización del control del trabajo, de los recursos productivos y del control de la generación y gestión de las instituciones políticas. De este modo, la ciudadanía puede llegar a servir como igualdad legal, civil y política para gentes socialmente desiguales.

Un Estado-nación es una suerte de sociedad individualizada entre las demás. Por eso, entre sus miembros puede ser sentida como identidad. Sin embargo, toda sociedad es una estructura de poder. Es el poder aquello que articula formas de existencia social dispersas y diversas en una totalidad única, una sociedad. Toda estructura de poder es siempre, parcial o totalmente, la imposición de algunos, a menudo cierto grupo, sobre los demás. Consecuentemente, todo Estado-nación posible es una estructura de poder, del mismo modo en que es producto del poder. En otros términos, del modo en que han quedado configuradas las disputas por el control del trabajo, sus recursos y productos; del sexo, sus recursos y productos; de la autoridad y de su específica violencia; de la intersubjetividad y del conocimiento. (QUIJANO, 2000, p. 15)

En acuerdo con un informe de la Comisión Económica para América Latina y el Caribe, uno de los mayores desafíos que enfrenta la región en su búsqueda por la igualdad es la inclusión de los derechos de los pueblos indígenas entre las prioridades de las políticas. Los desafíos son enormes, teniendo en cuenta que en América Latina, como se examina en este estudio, existen más de 800 pueblos indígenas, con una población cerca de 45 millones que se caracterizan por su diversidad demográfico, social, territorial y política, desde pueblos en aislamiento voluntario hasta su presencia en grandes asentamientos urbanos. A esto se agrega que el crecimiento económico registrado en la región es altamente dependiente en recursos naturales y de sus precios internacionales, en cuanto se observa un gobierno deficiente de estos recursos. La reprimarización de la economía causa fuerte presión sobre los territorios de los pueblos indígenas y provocó numerosos conflictos ambientales aún no resueltos. (CEPAL, 2015. p. 6).

Varios estudios señalan a un renacimiento de estos pueblos, en las dos últimas décadas del siglo pasado, dadas las medidas adoptadas en relación con el rescate de las identidades etnoculturales, su organización política y un nuevo modelo de gobernanza de los recursos naturales. Esto permitió la presentación de sus demandas al Estado y el reconocimiento de su existencia como sujetos de derecho - ciudadanía -, detentoras de una cultura y una forma de vida propios, haciendo valer así sus derechos.

Por ejemplo es posible indicar a entre otros aspectos los pueblos indígenas en América Latina, mejoras en la educación y en la salud. En relación con la educación, hubo un aumento en las tasas de asistencia escolar, con porcentajes de asistencia entre $82 \%$ y $99 \%$ de los niños de 6 a 11 años. En cuanto a salud, disminuyo la mortalidad infantil, de niños menores de cinco años, entre 2000 y 2010 en los nueve países con datos disponibles (Costa Rica, México, Brasil, Venezuela, Ecuador, Panamá, Guatemala, Perú y Bolivia). (ONU, 2014)

Junto con esto, el ancestral conocimiento, las innovaciones y las prácticas tradicionales de los pueblos indígenas para la conservación y la utilización sostenible de la diversidad biológica, así como el desarrollo de las distintas modalidades colectivas de las economías indígenas, ofrecen una valiosa oportunidad para la construcción de un nuevo paradigma de desarrollo, basado en un cambio estructural hacia la igualdad y la sostenibilidad. Es fundamental 
reconocer la contribución de los pueblos indígenas en los desafíos que trae el futuro de una América Latina soberana. (CEPAL: síntesis, 2015. p. 7).

La lucha de los pueblos indígenas por la defensa y el reconocimiento de sus derechos fue continua y persistente en la construcción de historia de los países latino americanos. Este legado de la reivindicación y reconocimiento gano espacio en un marco de derechos que se basa en dos grandes hitos: el Convenio sobre Pueblos Indígenas y Tribales de 1989 (núm. 169) de la OIT, que reconoce por primera vez sus derechos colectivos y la Declaración de las Naciones Unidas sobre los Derechos de los Pueblos Indígenas (2007), que propone el derecho de estos pueblos a la libre determinación. A su vez, el estándar mínimo de derechos de los pueblos indígenas, obligatorios para los Estados miembros se articula en cinco dimensiones: el derecho a la no discriminación; el derecho al desarrollo y bienestar social; el derecho a la integridad cultural; el derecho de propiedad, uso, control y acceso a tierras, territorios y recursos naturales; y el derecho a la participación política.

En el ámbito internacional existen dos mecanismos directos de la protección de los derechos humanos, incluidos los derechos de los pueblos indígenas: el sistema de las Naciones Unidas y del Sistema Interamericano de Derechos Humanos de la organización de Estados Americanos (OEA). En este último, las sentencias de la Corte Interamericana de Derechos Humanos, que tienen carácter vinculante para los Estados, fueron relevantes en el nuevo orden jurídico internacional en relación con los derechos de los pueblos indígenas. En el caso de las Naciones Unidas, órganos y mecanismos de protección adquieren una indiscutible importancia política para el reconocimiento y la aplicación de los derechos de los pueblos indígenas.

En ese contexto, S. James Anaya colabora diciendo que:

El sistema internacional contemporáneo reconoce abiertamente ahora que es un imperativo de derechos humanos el dar respuesta a las demandas de los pueblos indígenas. [...]. Sea como sea, lo cierto es que puede hablarse ahora de un régimen de derechos indígenas dentro del derecho internacional de los derechos humanos; un régimen todavía en desarrollo y que, en cierta medida, beneficia a los pueblos indígenas. (ANYA: 2004, p. 30)

De una forma objetiva, hay en el sistema universal de protección de los derechos humanos de las Naciones Unidas: a) mecanismos basados en la Carta de las Naciones Unidas, como el Consejo de Derechos Humanos, los procedimientos especiales, el examen periódico universal y órganos asesores (como, el Mecanismo de Peritos sobre los Derechos de los Pueblos Indígenas); (b) mecanismos basados en la aplicación de los principales tratados vinculantes del derecho internacional sobre de derechos humanos por los países que los han ratificado. Generalmente los mecanismos que también son llamados 'comités', hay presencia de especialistas. En términos de accesibilidad, hay varias posibilidades para presentar expedientes para Consejo de Derechos Humanos, los comités y procedimientos especiales, garantizando el acceso al sistema en caso de emergencias y urgentes demandas.

Sin embargo, hay mucho que evolucionar cuando analiza la cuestión indígena en América Latina. Se sabe que el patrimonio indígena consiste en la tierra en su dimensión territorial y en sus usos según las normas y costumbres de las sociedades nativas y, en este sentido hay necesidad de mejora. Por ejemplo se puede citar el Brasil. De las 1,113 tierras indígenas reconocidas, en proceso de reconocimiento por el estado o reclamadas por las comunidades, hasta agosto de 2016, sólo 398 o 35.7\%, tenía sus procedimientos administrativos terminados, es decir, fueron registrados por la Unión. (CIMI, 2016) 


\section{CUADRO 1 - Situación General de las tierras Indígenas en Brasil}

\begin{tabular}{|c|c|c|}
\hline Situación & Cantidad & $\begin{array}{l}\text { Porcentual } \\
\quad(5 \%)\end{array}$ \\
\hline $\begin{array}{l}\text { Registrados (demarcación completado y registrado en el Registro } \\
\text { Inmobiliario del Distrito y/o en Servicio de Patrimonio de la Unión) }\end{array}$ & 398 & 35.75 \\
\hline $\begin{array}{l}\text { Aprobado (con el Decreto de la Presidencia de la República y a la } \\
\text { espera de registro) }\end{array}$ & 15 & 1.34 \\
\hline $\begin{array}{l}\text { Declaradas (con Portaría Declaratoria del Ministerio de Justicia y } \\
\text { pendiente aprobación) }\end{array}$ & 63 & 5.66 \\
\hline $\begin{array}{l}\text { Identificado (reconocido como territorio tradicional por el grupo } \\
\text { técnico de la Funai y a la espera de declaratoria del Ministerio de } \\
\text { Justicia) }\end{array}$ & 47 & 4.13 \\
\hline $\begin{array}{l}\text { Identificadas (incluido en la programación de la Funai }{ }^{3} \text { para } \\
\text { identificación futura, con ya constituido grupos técnicos }\end{array}$ & 175 & 15.72 \\
\hline $\begin{array}{l}\text { Sin Acción (Tierras reclamadas por la comunidad que todavía no } \\
\text { aparecen en el listado de la Funai para estudio) }{ }^{4}\end{array}$ & 348 & 31.35 \\
\hline $\begin{array}{l}\text { Con Restricción (tierra que recibió el Presidente de la Funai } \\
\text { ordenanza restringiendo el uso de la zona el derecho de entrada, } \\
\text { locomoción o permanencia de personas extrañas a los marcos de la } \\
\text { Funai) }\end{array}$ & 6 & 0.53 \\
\hline $\begin{array}{l}\text { Reservadas (marcado como "reservas indígenas" en la época del } \\
\mathrm{SPI}^{5} \text { ) o Domínio (propiedad de las comunidades indígenas) }\end{array}$ & 61 & 5.48 \\
\hline $\begin{array}{ll}\text { Total } \\
\end{array}$ & 1.113 & 100 \\
\hline
\end{tabular}

Fonte: CIMI, 2016

La violencia contra las comunidades indígenas, en su mayoría corresponde a problemas de demarcaciones territoriales, ${ }^{6}$ ataques en los territorios, invasiones, deforestación, destrucción de propiedad, la explotación ilegal de recursos naturales, contaminación de manantiales y ríos, incendios, caza furtiva, y contaminación por plaguicidas, entre otras acciones que afectan a indígenas.

${ }^{3}$ La Fundación Nacional del indio (Funai) es el órgano indigenista oficial del Estado brasileño. Fue creado por ley 5 371, del 05 de diciembre de 1967. Está vinculado al Ministerio de justicia y tiene como objetivo central coordinar y realizar las políticas indígenas del Gobierno Federal, protegiendo y promoviendo los derechos de los pueblos indígenas. Además, las asignaciones de la Funai: identificar, delimitar, demarcar, regular y registrar las tierras ocupadas por pueblos indígenas, promover políticas orientadas al desarrollo sostenible de los pueblos indígenas y posibles impactos ambientales promovidos por agentes externos en aquellas tierras; Además de proporcionar a los pueblos indígenas, el acceso diferenciado a los derechos sociales y ciudadanía, tales como el derecho a la seguridad social y educación.

${ }^{4}$ La mayor número de tierras en la etapa Sin Acción se concentra en la Amazonía (130), seguida de Mato Grosso do Sul (68) y de los Estados de Rio Grande do Sul (24) y Rondonia (22).

${ }^{5}$ El Servicio de protección indígena (SPI) fue creado en 1910 con el fin de ayudar a la población indígena de Brasil. Con su fundación, la política indígena se convirtió en la responsabilidad del Estado Brasilero y no de instituciones religiosas, como se llevó a cabo desde la época colonial. En 1918, la Localización de los Trabajadores Nacionales pasó a formar un órgano propio. Entre 1930 y 1934, el SPI paso a pertenecer al Ministerio de Trabajo. Entre 1934 y 1939 paso a pertenecer al Ministerio de Guerra, por medio de la Inspectoría de Fronteras. En 1940, regresó al Ministerio de Agricultura y posteriormente pasó al Ministerio del Interior. El órgano ha organizado varias expediciones de reconocimiento en el territorio nacional, reuniendo grandes cantidades de información y objetos de los indios brasileños. Al inicio de la década de 1960, el órgano fue investigado por una Comisión parlamentaria de investigación debido a las denuncias de corrupción, genocidio y la ineficiencia. En 1967, ambos el SPI como el Consejo Nacional para la Protección de los Indios (el órgano encargado de formular la política indigenista brasileña) han sido sustituidos por la Fundación Nacional del indio (Funai).

${ }^{6}$ Según el Consejo Indígena Misionero, el retraso en la demarcación de tierras refuerza la sensación de abandono del Estado para las comunidades afectadas. Uno puede citar el caso de la Tierra Indígena (TI) San Gabriel/San Salvador, pueblo Kukama, ubicado en el municipio de Santo Antônio de Içá, en Amazonas, que tenía su Grupo Técnico creado en 25 de abril de 2003, mas, doce años más tarde, sus trabajos todavía no han sido concluidas. 
Sumado a este contexto, la deshumanización, la esclavitud, los poblados con pérdidas territoriales, la depreciación semántica generalizada y la tentativa de reducción linguística constituyen formas políticas violentas de negación de las diferencias y prácticas históricas de invisibilidad. Eso es lo que Boaventura de Sousa Santos (2003, p. 57) denomina conocimientoregulación, característico de la ciencia y del pensar moderno.

Dussel también advierte ante la cuestión de la colonialidad:

1. La civilización moderna se autodescribe como más desarrollada y superior (lo que significa sostener inconscientemente una posición eurocéntrica). 2. La superioridad obliga a desarrollar los más primitivos, bárbaros, como exigencia moral. 3. El camino de tal proceso educativo de desarrollo debe ser el seguido por Europa (es, de hecho, un desarrollo unilinear ya la europea lo que determina, nuevamente de modo inconsciente, la "falacia desarrollista"). 4. Como el bárbaro se opone al proceso civilizador, la praxis moderna debe ejercer en último caso la violencia, si es necesario, para destruir los obstáculos de esa modernización (la guerra justa colonial). 5. Esta dominación produce víctimas (de muchas y variadas maneras), violencia que es interpretada como un acto inevitable, y con el sentido casi-ritual de sacrificio; el héroe civilizador reviste a sus propias víctimas la condición de ser holocaustos de un sacrificio salvador (el indio colonizado, el esclavo africano, la mujer, la destrucción ecológica, etecetera). 6. Para lo moderno, el bárbaro tiene una "culpa" (por oponerse al proceso civilizador) que permite a la "Modernidad" presentarse no sólo como inocente sino como "emancipadora" de esa "culpa" de sus propias víctimas. 7. Por último, y por el carácter "civilizatorio" de la "Modernidad", se interpretan como inevitables los sufrimientos o sacrificios (los costos) de la "modernización" de los otros pueblos "atrasados" (inmaduros), de las otras razas esclavizables, el sexo por ser frágil, etecetera (Dussel, 2000: 49).

\section{PODER Y VIOLENCIA: CONCEPTOS Y DEFINICIONES}

De acuerdo con el concepto sociológico de poder, generalmente se define como la capacidad para imponer su voluntad a los demás, aunque estos resistan de alguna manera. Hay, en el contexto sociológico, varios tipos de poder: el poder social (del estado); poder económico (poder empresarial); el poder militar (poder político); entre otros. Mientras que de forma conceptual, se pueden destacar como importantes investigadores para el desarrollo de la concepción actual del poder en los trabajos de Max Weber ${ }^{7}$ y Pierre Bourdieu. ${ }^{8}$

Para Max Weber poder sería la probabilidad de un cierto comando con contenido específico sea obedecido por un grupo determinado. Bourdieu se preocupó con el poder simbólico que sería el poder invisible que sólo puede ser ejercido con la complicidad de aquellos que están sujetos a ese poder o incluso aquellos que lo ejercen. La violencia simbólica se basa en la fabricación continua de creencias en el proceso de socialización, que inducen a un individuo a posicionarse en el espacio social siguiendo criterios y normas del discurso dominante. Debido a este conocimiento del discurso dominante, la violencia simbólica es una manifestación de este

\footnotetext{
${ }^{7}$ Max Weber distingue básicamente tres tipos de dominación legítima: el tradicional, el carismático y racional legal. La primera tiene como su base el tradicionalismo y se basa en la creencia en la santidad de las costumbres en vigor, dando legitimidad a aquellos que están en el poder sólo por la tradición. La palabra clave para la comprensión de esa legitimidad es la aceptación de los privilegios tradicionales del soberano. La dominación tradicional tiene con tipos básicos el patriarcado y el patrimonialismo.

${ }^{8}$ El mundo social, para Bourdieu, debe entenderse a la luz de tres conceptos fundamentales: habitus, campo y capital.
} 
conocimiento a través del reconocimiento de la legitimidad de ese discurso dominante. Para Bourdieu, la violencia simbólica es el medio de poder simbólico. ${ }^{9}$

Habermas (1997) ${ }^{10}$ afirma que la violencia equivale siempre a la agresión física, por lo tanto exterior a lo simbólico. Sin embargo, esa crítica, además de restringir la violencia sólo a la dimensión física, ignora la posibilidad de la creencias dominantes imponen valores, hábitos y comportamientos sin recurrir necesariamente a la agresión física, creando situaciones donde el individuo que sufre la violencia simbólica se sienta disminuidas como ocurre, por ejemplo, en cuestiones relacionadas con el género, sexualidad, religión, entre otros. Es sabido que a través de diferentes formas y conceptos de diferentes pensadores respecto al tema poder, se puede analizar cuál es aplicable y cual las consecuencias que el poder puede tener cuando ese es objeto de construcción identitaria. ${ }^{11}$

Para Castells, las relaciones de poder son constitutivas de la sociedad porque quienes detentan el poder construyen las instituciones según sus intereses y valores. El poder se ejerce a través de la coerción (el monopolio de la violencia, legítimas o no, para el control del estado) y/o por la construcción de su significado en las mentes de las personas, a través de mecanismos de manipulación simbólica. Las relaciones de poder están incrustadas en las instituciones de la sociedad, particularmente en el Estado. Sin embargo, puesto que las sociedades son contradictorios y conflictivas, donde hay poder hay también contrapoder - consideramos que la capacidad de los actores sociales, desafían el poder incrustado en las instituciones de la sociedad con el objetivo de reivindicar la representación de sus propios valores e intereses. Todos los sistemas institucionales reflejan las relaciones de poder y sus límites tal como negociados por un interminable proceso histórico de conflictos y negociación. La configuración real del Estado y otras instituciones que regulan la vida de las personas depende de esa constante interacción entre el poder y el contrapoder.

La relación que se establece entre poder y la violencia, han sido objeto de estudios de varios investigadores. Antropólogos, filósofos, juristas, historiadores, sociólogos, entre otros. Sin embargo, todavía el tema en cuestión no sea una novedad en el cotidiano de las sociedades, actualmente se busca en forma incansable, conceptos, análisis, fórmulas teóricas, entre otras un consenso o ponderación para comprender la complejidad de esta unión: poder y violencia.

\section{VIOLENCIA CONTRA LAS COMUNIDADES INDIGENAS BRASILERAS: REFLECIONES INICIALES}

El agravamiento y la difusión de la violencia contra las comunidades indígenas ha sido objeto de debate en varias agencias nacionales e internacionales. A mediados del siglo XX, con los procesos de colonización en la Amazonia y otras regiones llevó a cabo un período de desterritorialización de los pueblos indígenas, con consecuencias directas sobre la dignidad humana. Más recientemente, se observó el ciclo de extracción desenfrenada sobre los recursos naturales por empresas nacionales y transnacionales seguidas de la ejecución de grandes obras civiles con impactos negativos sobre los ecosistemas, agravando el cuadro histórico del despojo y la vulnerabilidad. La ultima y mas más reciente etapa, versa acerca de la apropiación de los conocimientos tradicionales, la biodiversidad asociada a estos recursos genéticos, resultando en el extenso proceso histórico de despojo de los pueblos indígenas de América Latina.

La explotación de los recursos naturales próximo a las comunidades indígenas en Brasil alcanza básicamente a todos los Estados en un mayor o menor grado. Uno de los mayores

\footnotetext{
${ }^{9}$ Véase en O Poder Simbólico. Rio de Janeiro: Bertrand Brasil, 1992.

${ }^{10}$ Véase en Direito e democracia: entre facticidade e validade, volume I. Rio de Janeiro: Tempo Brasileiro, 1997.

${ }^{11}$ Para Habermas cuando más complejo para la sociedad, mayor será la racionalización a que se ve forzado su modo de vida. También acredita que la historia de las sociedades modernas es la historia de un intenso proceso de racionalización del modo de vida de las sociedades tradicionales
}

Revista de Direito Brasileira | São Paulo, SP | v. 19 | n. 8 | p. 20- 32 |Jan./Abr. 2018 
desastres ambientales de la historia brasilera afecto a tres pueblos indígenas en dos Estados: Los Tupiniquim y los Guaraní, en Espírito Santo y los Krenak, ${ }^{12}$ en Minas Gerais. En el Espíritu Santo, los relaves de la minera de la presa de Fundão, Samarco, que se rompió en Noviembre del 2015, azotó parte del territorio geográfico que ha impedido desde entonces a los pueblos indígenas ejercer la pesca tradicional, su principal actividad de subsistencia y riego de pastizales.

En Minas Gerais, el impacto en la comunidad Krenak también mató a los peces, contamino el agua y alcanzó la inmaterialidad, pues el río hace parte del colectivo en términos religiosos, social espiritual y artística. El grupo indígena Krenak ya estaba sufriendo los impactos provocados por grandes obras que rodean la comunidad. La comunidad se encuentra cerca de la central hidroeléctrica de Aimorés, construido en el cauce del Río Doce. En operación desde el año 2006, aún persisten muchos problemas causados por su instalación. Según el informe del Comité Especial de las Presas, aprobadas por el Consejo de Defensa de los Derechos de la Persona Humana (CDDPH) en 2010, la presa de Aimorés violo 11 derechos humanos, incluyendo la reparación por las pérdidas anteriores en la construcción de la presa. ${ }^{13}$

Los conocimientos indígenas constituyen importante aspecto del complejo de derechos socios ambientales, en que se caracterizan como manifestaciones propias de la cultura de las comunidades nativas. Este conocimiento transmitido por las comunidades indígenas, por muchas décadas, están vinculados a la diversidad social y biológica hasta el punto que se convierten en fundamentales para la preservación del medio ambiente y a menudo se confunde con su propia identidad. Otra adversidad experimentados por los pueblos indígenas es la apropiación de los conocimientos tradicionales.

Comunidades indígenas y pueblos cercanos dependen de los recursos biológicos para una variedad de propósitos cotidianos y se consideran a sí mismos como guardianes y protectores de la diversidad biológica. ${ }^{14}$ De esta manera, los conocimientos tradicionales han ayudado a preservar, mantener y aún aumentar la diversidad biológica a lo largo de los siglos.

Los conocimientos tradicionales asociados a la biodiversidad comprenden las técnicas de gestión de recursos naturales, métodos de caza y pesca, las propiedades farmacéuticas de las plantas, el conocimiento sobre los ecosistemas, las especies alimentarias y las diferentes formas de categorización de plantas y animales.

Sin embargo, debe observase que, en el caso de los pueblos tradicionales, el conocimiento producido no se relaciona sólo una fuente de utilidad, sino también a los valores simbólicos y espirituales tan importantes como los anteriores para la protección de su identidad (SANTILLI, 2005).

Según Iacomini (2009, p. 93-94), las empresas multinacionales y las instituciones científicas vienen sustrayendo y patentando los recursos biológicos y conocimientos indígenas sin autorización de los gobiernos, haciendo uso indiscriminado de la diversidad biológica, en el contexto económico en que opera.

\footnotetext{
${ }^{12}$ Los Krenák o Boruń se constituyen en los últimos de Botocudos do Leste, nombre dado por los portugueses a finales del siglo XVIII a los grupos que utilizan adornos - como botón o disco- labiales y auriculares. Son conocidos también como Aimorés, denominación dada por los Tupí. El Krenák pertenecen al grupo lingüístico Macro-Jê, hablando un lenguaje llamado Borun. Sólo mujeres mayores de 40 años son bilingües, mientras que los hombres, jóvenes y niños de ambos sexos son hablantes de portugués. En los últimos tres años haciendo esfuerzos para que los niños hable el Borun.

${ }^{13}$ Entre los principales factores, señalados el informe, que causan las violaciones de Derechos Humanos en la implementación de presas se pueden citar: derecho a la información y la participación, la precariedad y la insuficiencia de estudios ambientales llevado a cabo por los gobiernos federales y estatales y la definición restrictiva y limitada del concepto de éxito adoptado por las empresas.

${ }^{14}$ La Convención sobre Diversidad Biológica (CDB) establecido por el artículo 8 que los gobiernos deben respetar, preservar, mantener y promover el uso de los conocimientos tradicionales con la aprobación y participación de las comunidades indígenas y locales.
} 
La ilegitimidad debido a la ausencia de autorización de las comunidades tradicionales o del Estado se suma la falta de asignación justa y equitativa entre los sujetos involucrados. En esta dinámica se constata la apropiación de plantas, animales y conocimientos, así como las muestras de tejido, genes y células con potencial para ser explotado económicamente. La operación, es muy especializada, se caracteriza por el tráfico inicial de recursos naturales o de aprendizaje de los conocimientos tradicionales y posterior registro individual.

Comparato (2002, p. 539) alerta para la recurrente separación entre ética y tecnología en la historia humana para discurrir el desarrollo de habilidades técnicas en manos de unos pocos, sumado a la falta de contrapeso para el grado de sabiduría política para todos, engendra un permanente déficit ético que se corrobora tanto en oligarquías en el interior de las sociedades locales y en las relaciones internacionales. El resultado de esto son las grandes catástrofes manifiestas en masacres colectivas, hambrunas, epidemias, explotación denigrantes, fruto de segregación entre minoría y mayoría indigente.

\section{CONCLUSION}

En la investigación de la tríada, violencia, poder y las comunidades indígenas fue posible observar que independiente del tiempo el tema sigue siendo actual. La culminación de un proceso que comenzó en el siglo XV con la fundación de América y del capitalismo colonial juntada a la idea de poder le permite comprender la génesis de la violencia establecida en las comunidades indígenas de América Latina. De los distintos elementos se sabe que todavía hay aún mucho que avanzar en el proceso de demarcación y regularización de tierras indígenas. Se sabe que el 'no demarcación' potencializa y perpetúa los conflictos y hace aumentar el nivel de violaciones de los derechos y las violencias, incluso física, contra los pueblos indígenas.

Según la Constitución Federal de Brasil, todas las tierras indígenas tradicionales deben se han marcado hasta 1993, cinco años después de la promulgación de la Constitución. Sin embargo, según la estadísticas de CIMI, del 31 de agosto de 2016, 654 tierras indígenas en Brasil esperan actos administrativos del Estado para tener su proceso de demarcatorios finalizado. Este número corresponde al $58.7 \%$ del total de las 1113 tierras indígenas del país.

Además el retraso en la demarcación y regularización de tierras, hay muchas otras formas de violencia ejercidas contra las comunidades indígenas en la época contemporánea. Se niega la cultura, su lengua y trayectoria en la evolución de sus existencias milenarias ya que los modos de ser, hacer y vivir importunaban el pensamiento colonial. El proceso de ocupación y colonización de América trajo consigo las ideas de diferencia, el exotismo y la dominación. Este hecho y muchos otros, como la violencia de la asimilación forzada que hacen perder las característica de muchas comunidades, demuestra cómo los pueblos indígenas, la socio diversidad y la formación multiétnica de la sociedad de América Latina y en especial la brasileña fueron singularmente abordadas a lo largo de La historia. Inicialmente se dio origen al ocultamiento de la diversidad, después de la regulación jurídica inicial, marcada por el lado de la invisibilidad y de la negación de los derechos, seguida por los procesos de aculturación y asimilación - razón de una persistente racionalidad colonialista - que se resultó en diversas ocasiones, en enfrentamientos directos al derecho y a la justicia, además de detrimento de toda la riqueza cultural.

\section{REFERENCIAS BIBLIOGRÁFICAS}

ANAYA, S. James. Los pueblos indígenas em el derecho internacional. Tradução de Luis Rodrigues-Piñero Royo; Pablo Gutierrez Veja; Bartolomé Clavero. New York, USA. Ed.Trota, 2005. 
BOURDIEU, Pierre. O Poder Simbólico. Rio de Janeiro: Bertrand Brasil, 1992.

BRIGHENTI, Clovis A. O “desenvolvimento" versus os povos indígenas. In: CIMI. Relatório: Violência contra os povos indígenas no Brasil. Dados 2014. Brasília: Cimi, 2015.

- Colonialidade do poder e a violência contra os povos indígenas. In: Revista PERCURSOS. Florianópolis, v. 16, n.32, p. 103-120, set./dez. 2015.

COLACO, Thais. L.; COSTA, José Augusto Fontoura (Org.). Pueblos indígenas, desarrollo y participación democrática. 1. ed. Florianópolis e Oñati: Fundação Boiteux e Instituto Internacional de Sociologia Jurídica de Oñati, 2009.

. El reconocimiento constitucional del derecho y la jurisdicción indígena como afirmación de la autodeterminación de los pueblos indígenas. In: Alegatos, v. 87, p. 241-258, 2014.

COMPARATO, Fábio Konder. A afirmação histórica dos direitos humanos. 7. ed. São Paulo: Saraiva, 2010.

DUSSEL, Enrique. Para una ética de la liberación latino-americana. V. I-II. Buenos Aires: Siglo Veintiuno Editores, 1973.

. Europa, modernidad y eurocentrismo. In: La colonialidad del saber: eurocentrismo y ciencias sociales, perspectivas latino-americanas. Buenos Aires: Clacso, 2000.

FRASER, Nancy. Da redistribuição ao reconhecimento? Dilemas da justiça na era pós-socialista. In: SOUZA, Jessé (org). Democracia hoje: novos desafios para a teoria democrática contemporânea. Brasília: UnB, 2001.

HABERMAS, Jürgen. Direito e democracia: entre facticidade e validade. Vol. I. Rio de Janeiro: Tempo Brasileiro1997.

PEREIRA, Ana Cristina Paulo. A proteção patentária interna e internacional: implicações do Acordo TRIPS/OMC na ordem jurídica brasileira. Rio de Janeiro: Lumen Juris, 2009.

SANTILLI, Juliana. Socioambientalismo e novos direitos: proteção jurídica à diversidade biológica e cultural. São Paulo: Peirópolis, 2005.

SOUSA SANTOS, Boaventura. La globalización del derecho: los nuevos caminos de la regulación y la emacipación. Bogotá: Universidad Nacional de Colômbia/ILSA-Instituto Latinoamericano de Servicios Legales Alternativos, 1998.

ZAFFARONI, E. Raúl. El Derecho latinoamericano en la fase superior del Colonialismo. In: Revista Pensar en derecho. FERREYRA, Raúl Gustavo. El principio de subordinación como fundamento del Estado constitucional. Su regulación en Argentina, Brasil, Colombia, Ecuador y México, 2014. 
WEBER, Max. Economía y sociedad: esbozo de sociología compreensiva. Fondo de Cultura Económica-Sección de obras de sociología, 1964.

WOLKMER, Antonio Carlos; FERRAZZO, D. . Sistemas Plurais de Direito: desde Práticas Sociais e Insurgências Latino-Americanas. In: Revista Direito, Estado e Sociedade. , v. 48, p. 47$75,2016$.

\section{FUENTES ELECTRONICAS}

BALLESTRIN, Luciana. Colonialidade e Democracia. In: Revista Estudos Políticos, v. 5, nº 1. Rio de Janeiro: UFF. Disponível em: http://revistaestudospoliticos.com/wpcontent/uploads/2015/02/Vol.5-N.1-p.191-209.pdf. Acesso em 12 de out. 2017.

Comissão Econômica para a América Latina e Caribe (CEPAL/ONU). Los pueblos indígenas en América Latina. Avances en el último decenio y retos pendientes para la garantía de sus derechos. Síntesis. Chile: Imprensa Oficial, 2015. Disponível em: http://www.cepal.org/es/publicaciones. Acesso em 20 de set. 2016.

Conselho Indigenista Missionário. CIMI. Relatório - Violência contra os povos indígenas no Brasil. Dados de 2015.20 Disponível http://www.cimi.org.br/pub/relatorio2015/relatoriodados2015.pdf. Acesso em 20 de fev. 2017.

Comissão Pastoral da Terra (CPPT/Brasil). Centro de Documentação - Dados e Notas. Disponível em: https://cptnacional.org.br. Acesso em 03 de mar. 2017.

Convenção sobre Diversidade Biológica (ABS). In: Conhecimentos Tradicionais. Trad. Carlos Potiara Castro. Montreal, 2012. Disponível em: https://www.cbd.int/abs/infokit/revised. Acesso em 25 de set. 2016.

DUSSEL, Enrique. Transmodernidade e interculturalidade: interpretação a partir da filosofia da libertação. In: Revista Soc. estado. vol. $31 \quad \mathrm{n}^{\circ} .1$ Brasília. Disponível em: http://www.scielo.br/scielo.php. Acesso em 31 de jan. 2017.

KUJAWA, Henrique Aniceto. Conflitos envolvendo indígenas e agricultores no Rio Grande do Sul: dilemas de políticas públicas contraditórias. In: Revista Ciências Sociais Unisinos. São Leopoldo, $2015 . \quad$ Disponível em http://revistas.unisinos.br/index.php/ciencias_sociais/article/viewFile/csu.2015.51.1.08/4601. Acesso em 02 de fev. 2017.

LANDER, Edgar. A colonialidade do saber: eurocentrismo e ciĺncias sociais. Perspectivas latinoamericanas. In: Colección Sur Sur, CLACSO, Buenos Aires, Argentina, 2005. Disponível em http://bibliotecavirtual.clacso.org.ar/. Acesso em 21 de fev. 2017.

Movimento de Atingidos pela Barragem (MAB). Relatório da Comissão Especial das Barragens. In: Conselho de Defesa dos Direitos da Pessoa Humana (CDDPH). Brasília, 2010. Disponível em: http://www.sdh.gov.br. Acesso em 25 de set. 2016. 
Organização das Nações Unidas (ONU). Relatório da $1^{\text {a }}$ Conferência Mundial sobre os Povos Indígenas. Nova Iorque, 2014. Disponível em: https://nacoesunidas.org/

Las tecnologías de la información y las comunicaciones para el desarrollo. Declaração das Nações Unidas sobre os Direitos dos Povos Indígenas (A/RES/61/295), 2007. Disponível em http://www.un.org/es/comun/docs. Acesso em 13 de set. 2016.

Organização Internacional do Trabalho (OIT). Convenio 169. Disponível em: http://www.ilo.org/indigenous/Conventions/no169/. Acesso em 10 de set. 2016.

QUIJANO, Aníbal. Colonialidad del poder, eurocentrismo y América Latina. In: La colonialidad del saber: eurocentrismo y ciencias sociales. Perspectivas Latinoamericanas. Edgardo Lander (comp.) CLACSO, Consejo Latinoamericano de Ciencias Sociales, Buenos Aires, Argentina, 2000. Disponível em: http://bibliotecavirtual.clacso.org.ar/ar/libros/lander/quijano.rtf. Acesso em 23 de fev. 2017.

WALSH, Catherine. Interculturalidad, Estado, Sociedad: Luchas (de) coloniales de nuestra época. Quito: Universidad Andina Simón Bolivar, Ediciones Abya-Yala, 2009. Disponível em: http://www.flacsoandes.edu.ec/interculturalidad/wp-content/uploads/2012/01/Interculturalidadestado-y-sociedad.pdf. Acesso em: 15 de agosto de 2016. 